\title{
Benefit-Risk Assessment of Fish Oil in Preventing Cardiovascular Disease
}

\author{
Bill Lands ${ }^{1,2,3}$
}

Published online: 13 July 2016

(c) The Author(s) 2016. This article is published with open access at Springerlink.com

\begin{abstract}
Cardiovascular disease (CVD) is a preventable disease, which combines two general processes: chronic vascular inflammation and acute thrombosis. Both are amplified with positive feedback signals by $n-6$ eicosanoids derived from food-based n-6 highly unsaturated fatty acids (n-6 HUFA). This amplification is lessened by competing actions of n-3 HUFA. Death results from fatal interactions of the vascular wall with platelets and clotting proteins. The benefits of fish oil interventions are confounded by complex details in pharmacokinetics, pharmacodynamics, adverse events, timescale factors, topology, financial incentives and people's sense of cause and effect. Two basic aspects of n-3 HUFA that are overlooked in CVD dynamics are saturable, hyperbolic responses of the enzymes continually supplying n-6 HUFA and hard-tocontrol positive feedback receptor signals by excessive $n-6$ HUFA-based mediators. Multiple feedback loops in inflammation and thrombosis have diverse mediators, and reducing one mediator that occurs above its rate-limiting levels may not reduce the pathophysiology. Clinicians have developed some successful interventions that decrease CVD deaths in the form of secondary prevention. However, the current high CVD prevalence in the USA remains unchanged, and successful primary prevention of CVD remains uncertain. This review weighs the available evidence to help clinicians, the biomedical community and the
\end{abstract}

\footnotetext{
Bill Lands

wemlands@att.net

1 American Society for Nutrition, Rockville, MD, USA

2 American Association for the Advancement of Science, Washington, DC, USA

36100 Westchester Park Drive, \#1219, College Park, MD 20740, USA
}

public put the use of fish oil supplements into a balanced perspective.

\section{Key Points}

The hyperbolic dynamics of enzyme-catalysed processes and the hard-to-control, explosive nature of positive feedback signals are often overlooked in the design and interpretation of cardiovascular disease (CVD) interventions.

Among apparently normal human populations with different ethnic food habits, the highly unsaturated fatty acid (HUFA) balance (\% n-6 in HUFA) in blood lipids ranges from $25 \% \mathrm{n}-6$ in HUFA to $85 \%$ $\mathrm{n}-6$ in HUFA.

The $\%$ n- 6 in HUFA in blood lipids relates directly to the omega 3-6 balance of the foods ingested and also to the intensity of the resulting n- 6 eicosanoidrelated chronic health disorders.

In the absence of $n-3$ nutrients, the essential dietary nutrient $\mathrm{n}-6$ linoleic acid has a very narrow therapeutic window between efficacy and harm, which is widened by $n-3$ HUFA in fish oil supplements.

Dietary fish oil could be a successful supplement in primary preventive interventions in CVD that balance the intakes of n-3 and n- 6 nutrients and maintain balanced n-3 and n-6 HUFA in tissues. 


\section{Introduction}

Assessing the benefits and risks of fish oil supplements in reducing harm from cardiovascular disease (CVD) addresses an urgent need to understand effective ways to prevent ill-informed food choices from causing sickness and death. The US Centers for Disease Control and Prevention (CDC) describes CVD as a preventable disease [1], while its prevalence continues little diminished [2]. A growing interest in using fish oil to prevent CVD is seen in the US National Library of Medicine PubMed database, which lists over 4500 scientific reports from 1960 to the present (Fig. 1). While abundant data on efficacy and adverse effects exist, their orderly assembly has not yet provided broad agreement on an effective way to handle this approach to CVD. The lack of success is due in part to cursory handling of the connected molecular actions that mediate pharmacokinetics, pharmacodynamics, adverse events, timescale factors, financial incentives and people's sense of cause and effect. These combine to burden statistical rigour and logic, tempting people into hasty conclusions about benefit and risk.

Perseverance and rigorous logic are needed to integrate the many CVD concepts into multi-compartment models that correctly represent the complex reality that occurs when a person ingests $n-3$ and $n-6$ nutrients. Oversimplified mono-compartment and two-compartment models are often used to interpret clinical trials of patented medications. However, the complexity is much greater for n-3 nutrient actions than for most medications. Dietary essential n-3 fatty acids act continually in the presence of abundant competing n-6 homologues, and both $n-3$ and $n-6$ highly

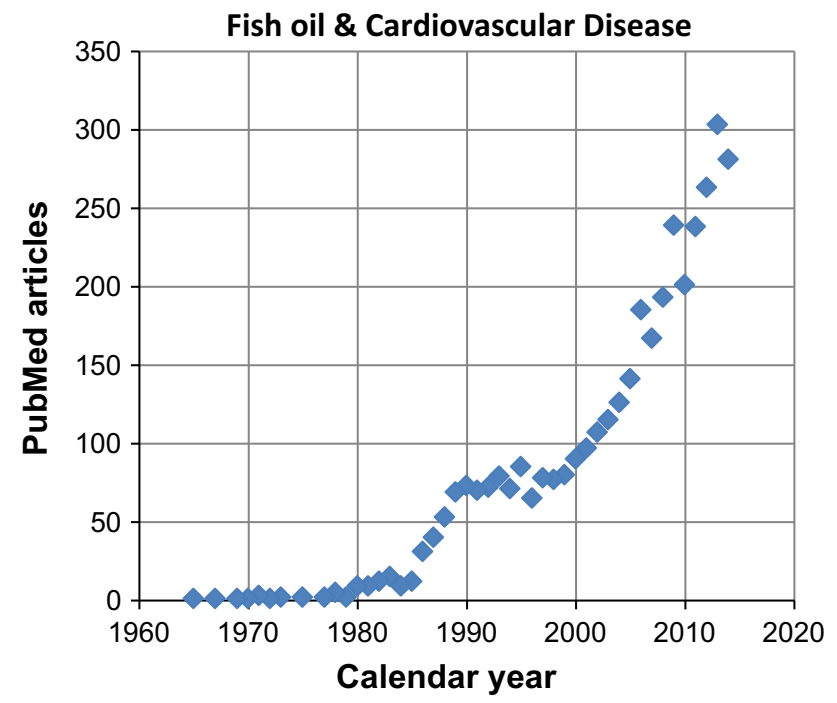

Fig. 1 Scientific reports on fish oil and cardiovascular disease. A search of PubMed (http://www.ncbi.nlm.nih.gov/pubmed/) for 'fish oil cardiovascular disease' in January 2016 retrieved 4585 reports unsaturated fatty acids (HUFA) form important bioactive mediators. This review weighs the available evidence to help clinicians, the biomedical community and the public put the use of fish oils into a balanced perspective.

\section{Balancing Three Aspects: Risk, Benefit and Dose}

\subsection{Risk and Surrogate End Points}

The current risk of CVD among Americans is great. The National Heart, Lung, and Blood Institute (NHLBI) has noted that two thirds of Americans over 60 years of age have CVD, and it killed 788,000 in 2010 (see pages 33, 41 and 47 in Ref. [2]). The need for interventions that lower the risk is obvious. However, 788,000 deaths each year mean that only about 25 per 10,000 Americans die of CVD, while 9975 do not. This makes the statistics of primary prevention a difficult challenge. Clinicians would need to intervene consistently with thousands of people for many years to see significant primary prevention of CVD deaths. To design more statistical power, CVD trials often monitor surrogate end points that occur sooner and with more frequency than death. They also recruit individuals already likely to have preclinical CVD, making trials more like secondary than primary interventions.

Biomarkers consistently predicting the risk of fatal CVD events are often used hopefully as a surrogate end point. Assessment of risk depends on the end point being a valid surrogate for CVD death, i.e. causally connected to CVD death. However, some predictive biomarkers are comorbidities that result from a common underlying process. They are only associated factors with no direct causal role in CVD. In reviewing the limited success of several large and expensive CVD trials, the NHLBI director noted in 1987 that "There is no question that surrogate end points are a big issue" [3]. Large clinical trials using comorbid conditions and biomarkers that strongly predict the risk of CVD have lowered the presumed surrogates without significantly lowering CVD death rates. Such trials have included lowering obesity without reducing the CVD event rate [4]; lowering blood cholesterol with dietary n-6 linoleic acid (LA; 18:2n-6) but increasing the CVD death rate [5]; and intensive control of blood glucose in type 2 diabetic patients but an increased CVD death rate [6]. These interventions changed biomarkers but did not prevent the path to CVD.

With regard to CVD and fish oil supplements, many physicians seem uninformed about the physiological roles and amounts of n-3 and n- 6 nutrients in foods. Analysis of 17 randomized, controlled cardiovascular clinical trials showed a disappointing risk ratio (RR) of 0.97 for 'diet advice' from physicians, while benefits were clearly 
evident for using n-3 supplements, with an RR of 0.77 [7]. Hindsight suggests that successful CVD clinical trials will use surrogate biomarkers that are within the chain of molecular actions connecting food habits to death. The n-3 HUFA in fish oils operate in such pathways, and the HUFA balance ( $\% \mathrm{n}-6$ in HUFA) is a valid biomarker for the outcomes of those pathways.

Inflammation and thrombosis in CVD are amplified by positive feedback signals from food-based $n-6$ mediators [8]. Ecological observations have suggested primary preventive interventions that might succeed. For example, an unintended beneficial intervention showed a food-based origin for CVD when the lower rate of CVD in Europe during the Second World War reversed afterwards (reviewed in Ref. [9]). An unintendedly harmful intervention resulted in higher rates of CVD in Japanese migrants in Brazil who ate less fish and had lower n-3 HUFA levels in plasma phospholipids [10].

Similar differences occurred with Japanese migrants in Minnesota who adopted new food habits [11]. Different intakes of n-3 and n- 6 nutrients (rather than genetic differences) gave HUFA balances of $37 \% \mathrm{n}-6$ in HUFA for rural Japanese, $44 \%$ for urban Japanese, $74 \%$ for Japanese Americans and $81 \%$ for Caucasian Americans [11]. Heart attacks were much less frequent among traditional Japanese (with about $35 \%$ n-6 in HUFA) and Inuits (with about $25 \%$ n-6 in HUFA) eating large amounts of marine foods rich in n-3 HUFA [9]. People maintaining $>50 \% \mathrm{n}-6$ in HUFA throughout their lifetime clearly have a greater risk of CVD death than people with $<50 \% \mathrm{n}-6$ in HUFA $[12,13]$. Clinical trials have not yet examined clinical outcomes from long-term HUFA balances near $50 \%$ n-6 in HUFA.

\subsection{Benefit and Comorbidities}

The benefit of not dying and of reducing a cause of dying seems obvious (though hard to quantitate), whereas benefit from reducing an associated predictive biomarker requires caution. Reducing a non-causal biomarker may give little benefit in reducing CVD death [4-6]. On the other hand, when comorbidities are caused by a common underlying process, reducing that process may give many more benefits than expected. Too narrow a focus on one disease can neglect important benefits. Figure 2 notes many chronic health conditions that are made worse by excessive actions of n-6 HUFA-based products of the arachidonic acid cascade $[8,14]$. The use of fish oil supplements to balance $n-3$ and $\mathrm{n}-6$ HUFA precursors beneficially diminishes inflammation and thrombosis plus many other comorbidities (Fig. 2). Such pleiotropy is seldom encountered (and often ignored) in drug efficacy trials, for which limited benefits are more easily assessed.
Health Conditions Linked to HUFA Balance

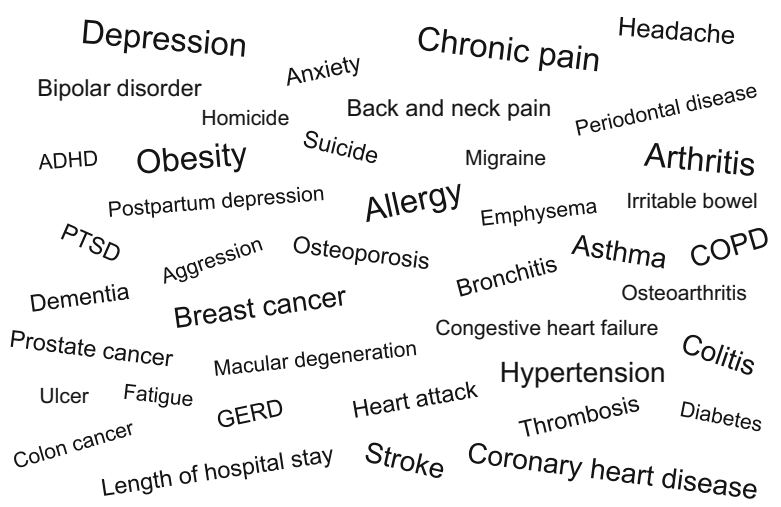

Fig. 2 Health conditions linked to the highly unsaturated fatty acid (HUFA) balance. $A D H D$ attention deficit-hyperactivity disorder, COPD chronic obstructive pulmonary disease, GERD gastroesophageal reflux disease, PTSD post-traumatic stress disorder

Occupational medicine experts have identified dozens of chronic health conditions other than CVD that cause major health-related financial losses for US corporations $[15,16]$. Many of these conditions (see Table 1 in Ref. [8]) are made worse by excessive $n-6$ actions, and the HUFA balance is linked to financial loss (see Fig. 2 in Ref. [14]). The balance of n-3 and n-6 HUFA in blood lipids [17] is a valuable surrogate for monitoring food-based interventions. Ironically, CVD (the top cause of death) is not among the top ten conditions causing health-related financial losses (see Fig. 1 in Ref. [15]), and many other food-based health conditions with excessive actions of $n-6$ eicosanoids [16, 18] cause the top ten financial losses [15]. Interventions with fish oil that lower the HUFA balance and the prevalence of CVD and n-6-mediated comorbid conditions will likely give large overall benefits measured in terms of lower health-related financial losses and a greater sense of wellbeing $[14,16,18]$.

\subsection{Dose and Therapeutic Windows}

Clinical trials are often designed to assess actions of patented drugs that are not found in humans. Pharmacokinetic and pharmacodynamic actions often occur in minutes or hours as drugs are metabolized and excreted, and most adverse effects are recognized quickly. Increased doses give increased benefits until undesired events become evident at higher doses. This occurs with antiinflammatory and anti-thrombotic drugs $[19,20]$. When the therapeutic window is narrow, prudent practice uses the beneficial drug at its lowest effective dose and monitors its levels continually to avoid adverse events [21].

To illustrate complex CVD-related conditions in which actions of fish oil supplements can be evaluated, this article 
notes some pharmacokinetic and pharmacodynamic actions of aspirin on CVD processes. Both aspirin and fish oil are rapidly absorbed and rapidly removed (aspirin by hydrolysis and fish oil by incorporation into tissue phospholipids). Both give pleiotropic benefits by slowing the arachidonic acid cascade pathway [8] and decreasing harmful positive feedback signals by $n-6$ eicosanoids. A major difference in action is that aspirin rapidly and irreversibly inhibits the cyclooxygenase that forms $n-6$ eicosanoids in the pathophysiological chain of events, and it has a narrow therapeutic window above which many serious adverse events occur [18]. In contrast, the n-3 HUFA in fish oil (20:5n-3, 22:5n-3, 22:6n-3) competitively and reversibly displace n-6 mediators at multiple steps in the metabolic and pathophysiological chains of events $[8,18]$, and supplemental intakes of n-3 HUFA at doses up to $5 \mathrm{~g}$ /day do not raise safety concerns for adults [22].

Essential n-3 and n-6 nutrients accumulate in tissue lipids and are released during the following weeks or months. LA (18:2n-6) accumulates as $10-20 \%$ of the weight in adipose fat [23], which is often one third of an individual's total body mass. Fat is continually released from adipose into plasma as non-esterified fatty acids (NEFA), which circulate bound to albumin. The 2- to 4-min half-life of NEFA allows the small transient plasma pool $(500 \mu \mathrm{mol} / \mathrm{L})$ to transport over $2500 \mathrm{kcal}$ of energy in $24 \mathrm{~h}$. This is near the average daily energy expenditure of adult Americans. Importantly, 10-20\% of the circulating NEFA may be n-6 LA, which has a narrow therapeutic window [18]. Prudent practice would be to ingest $n-6$ LA at its lowest effective dose (see Sect. 4.1) and monitor its n-6 HUFA products to avoid adverse conditions.

An efficient elongation-desaturation pathway [18] continually converts circulating LA (3.4 mM in plasma [24]) into the major n-6 HUFA, arachidonic acid (20:4n-6), plus 20:3n-6, 22:4n-6 and 22:5n-6. It also converts alpha-linolenic acid (ALA; 18:3n-3) into the n-3 HUFA (20:5n-3, 22:5n-3 and 22:6n-3) also present in fish oil. The n-3 and n-6 HUFA readily esterify into tissue phospholipids [25], from which accumulated HUFA are released and form potent eicosanoids $[8,26]$. Their competing beneficial and harmful actions create the environment into which Americans introduce the n-3 HUFA of supplemental fish oil to cut CVD risk, and the \% n-6 in HUFA can be used to monitor the intervention's effectiveness.

\section{Balancing Two Timescales in Cardiovascular Risk}

Two processes with vastly different timescales combine to cause a fatal heart attack: (1) slow, decades-long inflammatory damage to the vascular wall; and (2) sudden formation of platelet aggregates, which stop the flow of oxygenated blood to the heart or brain. Both inflammation and thrombosis involve excessive actions of food-based $n-6$ products of the arachidonic acid cascade, which are diminished by $n-3$ nutrients.

\subsection{Long-Term Chronic Inflammatory Damage}

CVD is a progressive, chronic inflammatory disorder [27], which begins in adolescence and increases steadily with age [28]. Autopsy specimens from all American teenagers studied have had evident vascular damage. The damaged surface area of the abdominal aorta was near $20 \%$ at 18 years of age, $32 \%$ at 28 years of age and $40 \%$ at 32 years of age. Continual initiation of vascular damage proceeds unrecognized for decades until the accumulated damage eventually creates clinical signs and symptoms of CVD. The steady inflammatory progression results in a high prevalence of CVD among Americans; nearly $40 \%$ of 40 -year-old, $60 \%$ of 60 -year-old and $80 \%$ of 80 -year-old have CHD [1]. Successful primary prevention needs to start in adolescence and prevent repeated exposures to foodbased vascular insults and injuries.

CVD begins when postprandial food energy creates transient dysfunction in the arterial endothelium, recruiting and activating monocytes, which differentiate into macrophages and progressively form inflammatory plaques [18]. The plaques start to develop in regions of turbulent eddy flow, where residence times are longer and inflammatory chemokines, cytokines and adherent cells can accumulate $[29,30]$. These recruit more inflammatory cells, which further create and amplify chronic inflammatory conditions and eventually form the foam cells that are characteristic of atherosclerosis. Increased food energy intake raises circulating levels of cholesterol and phospholipid, and increased energy expenditure lowers them [31, 32]. This makes circulating cholesterol a biomarker associated with repeated transient postprandial energy excesses, and the 1984 Cholesterol Consensus Conference report urged vigorous control of food energy to prevent CVD [33]. That has not yet occurred.

\subsubsection{Transient Energy Excess and Oxidant Stress}

The average rate of energy expenditure is important for understanding energy balance in modern American lifestyles. Many current activities burn only about $200 \mathrm{kcal}$ in $3 \mathrm{~h}$ : sleeping, eating, riding in public transport, standing in line, using computers, reading, watching television or driving a car [18]. During $3 \mathrm{~h}$ after a typical American restaurant meal of $1327 \mathrm{kcal} \mathrm{[34],} \mathrm{the} \mathrm{liver} \mathrm{converts} \mathrm{the}$ extra $1000 \mathrm{kcal}$ into triacylglycerols and cholesterol and secretes them as very low-density lipoprotein (VLDL). 
Every large meal gives lots of NEFA released from chylomicrons and VLDL by lipoprotein lipase tethered to a glycoprotein on endothelial cell surfaces [18].

Transient postprandial NEFA act with peroxisomes and mitochondria to produce reactive oxygen species, which impair endothelial function [35, 36]. NEFA also activate protein kinase $\mathrm{C}$, which further increases production of reactive oxygen species by nicotinamide adenine dinucleotide phosphate (NADPH) oxidase. The increase in oxygen-derived free radicals impairs formation of antithrombotic prostacyclin (PGI), quenches nitric oxide and suppresses endothelial-mediated dilation [37]. It also oxidizes phospholipids and activates the nuclear factor (NF)$\mathrm{kB}$ signalling pathway, which induces transcription of the genes that form inflammatory chemokines and cytokines and promote more inflammation plus apoptotic death of endothelial cells, with further recruitment of inflammatory cells $[38,39]$. Three meals per day give 1000 occasions annually in which transient, reversible local endothelial dysfunction might convert into a chronic inflammatory locus. Each instance in which a transient oxidative insult does not resolve may start a chain of events that eventually becomes an atherosclerotic plaque.

\subsubsection{Preventing Endothelial Dysfunction with Fish Oil}

Fish oil supplementation increases nitric oxide availability and diminishes transient postprandial oxidative stress and vascular dysfunction [40, 41]. Eating n-3 HUFA maintains endothelial integrity with increased numbers of endothelial progenitor cells and reduced numbers of endothelial microparticles [42]. Improved bioavailability and function of endothelial progenitor cells [43] may be how marine diets have protected some ethnic groups from the epidemic of progressive vascular damage seen in the USA. Fish oilenriched diets give a HUFA balance that improves endothelial progenitor cell function [44] and decreases the occasional transition to chronic inflammatory pathophysiology.

Local vascular inflammation is amplified further by the potent chemotactic n-6 leukotriene $\mathrm{B}_{4}\left(\mathrm{LTB}_{4}\right)$. It is formed from the n-6 HUFA arachidonic acid by 5-lipoxygenase (rather than the cyclooxygenases that form prostanoids) [8]. The n- $6 \mathrm{LTB}_{4}$ acting with the BLT-1 receptor promotes atherosclerosis by (1) enhancing recruitment, adhesion and activation of inflammatory leukocytes; (2) providing an amplifier loop of monocyte chemotaxis via chemokine (C-C motif) ligand 2 (CCL2) production; and (3) converting monocytes into foam cells through enhanced expression of CD36 and fatty acid accumulation [45, 46]. When the tissue HUFA balance has more $n-3$ than $n-6$, the 100-fold weaker action of the n-3 LTB $_{5}$ [47] competitively moderates unwanted n-6 actions. Such moderation seems evident in the 25-year, longitudinal Seven Countries Study initiated by Ansel Keys. The biomarker for imbalanced food energy intake and expenditure-blood cholesterolwas associated positively with CVD death in Northern Europe and the USA (where the average $\% \mathrm{n}-6$ in HUFA was near 75-80\%) but not in Japan [48-50] (where the average \% $\mathrm{n}-6$ in HUFA was near 40-50\%).

Dietary habits produce predictably different proportions of $n-3$ and n-6 HUFA in tissue phospholipids $[12,51]$ and different risks of CVD death [13]. The extent to which the food energy biomarker, blood cholesterol, correlated with CVD death was related directly to the extent to which the pro-inflammatory biomarker, $\%$ n-6 in HUFA, exceeded the less inflammatory $\% \mathrm{n}-3$ in HUFA $[18,51]$. The added possible formation of anti-inflammatory, pro-resolving actions of n-3 HUFA derivatives (resolvins, maresins and protectins [52]) further indicates a benefit from higher proportions of $n-3$ in HUFA. Endothelium with a high \% n-3 in HUFA may recover more readily from transient postprandial NEFA insults, whereas a high \% $\mathrm{n}-6$ in HUFA may amplify transient insults into chronic inflammatory injury [8, 17]. Because tissue HUFA proportions predictably relate to average dietary intakes of 11 different n-3 and $n-6$ nutrients [50], the HUFA balance is a useful biomarker of nutrient intakes and also a valid surrogate for chronic vascular damage and eventual CVD death. This biomarker and enhanced endothelial injury from food energy could serve as valid surrogates for a CVD prevention trial. This aspect is discussed in Sect. 4.2 with regard to designing an effective dose for fish oil interventions.

\subsection{Acute Thrombotic Events}

Cardiovascular death results from fatal interactions of an impaired vascular wall with platelets and clotting proteins. Decades of inflammatory vascular damage [28] progressively increase the likelihood of some event triggering activation, adhesion and aggregation of platelets and formation of a thrombus. Thrombosis involves multiple agonists with positive feedback signals causing platelet shape change and granule secretion, which activates other platelets, promotes wound repair and initiates inflammatory responses [53]. In healthy people, platelet-mediated thrombotic processes are balanced by potent anti-thrombotic agonists released from healthy vascular endothelial cells.

\subsubsection{Multiple Amplifier Cascades}

Many agonists activate platelets to aggregate: collagen, fibrinogen, von Willebrand factor, adenosine diphosphate (ADP), serotonin, thrombin, epinephrine and arachidonic acid [54]. Their actions are amplified by thromboxane A (TXA) [55], formed by the arachidonic acid cascade [8]. 
Platelet cyclooxygenase converts n-3 and n-6 HUFA into the hydroperoxide, prostaglandin $\mathrm{G}\left(\mathrm{n}-3 \quad \mathrm{PGG}_{3}\right.$ and $\mathrm{n}-6$ $\mathrm{PGG}_{2}$ ) [8]. PGG is reduced to the hydroxyl form, $\mathrm{PGH}$, and thromboxane synthase converts PGH into the very unstable TXA [56]. TXA spontaneously decomposes with a half-life of $30 \mathrm{~s}$, which limits its action on the selective TXA receptor, TP. TP action releases calcium $\left(\mathrm{Ca}^{2+}\right)$ and ADP $[55,57]$ and promotes an 'oxidant burst', which forms $\mathrm{H}_{2} \mathrm{O}_{2}$ while also activating phospholipase $\mathrm{A}_{2}$-catalysed release of HUFA from platelet membranes.

The released hydroperoxide activator and HUFA substrate amplify more cyclooxygenase-catalysed formation of PGG, PGH and TXA, which trigger more aggregation and release of more activating agents. The need for hydroperoxide activation by cyclooxygenase and lipoxygenase activities to produce more activating hydroperoxides $[57,58]$ illustrates the explosive nature of fatty acid oxygenase actions $[59,60]$. Lowering the local abundance of hydroperoxide activators by cellular peroxidases slows the arachidonate cascade and enhances the inhibitory efficacy of n-3 HUFA and certain anti-inflammatory drugs [61, 62].

Slower formation of hydroperoxide product/activator (PGG) by $n-3$ HUFA (20:5n-3) relative to $n-6$ HUFA $(20: 4 n-6)[59,63,64]$ makes the formation and action of $\mathrm{n}-3$ autacoids less intense than those of n-6 autacoids $[8,26]$ and more vulnerable to suppression by peroxidases. Amplified signals during platelet aggregation stimulate much more $\mathrm{PGH}_{2}$ and $\mathrm{TXA}_{2}$ formation than is needed. As a result, inhibition of ex vivo serum $\mathrm{TXB}_{2}$ formation must be virtually complete before thromboxane-dependent in vivo platelet aggregation is diminished [65].

The PGH formed in vivo by activated platelets can diffuse to adjacent healthy endothelial cells, which have a PGI synthase that converts PGH into the relatively stable and potent anti-thrombotic agent PGI [66-68]. Platelet/vascular wall interactions have pro-thrombotic thromboxane and antithrombotic PGI acting in adjacent cells, and bleeding times give a crude estimate of the in vivo balance in plateletendothelium interactions [65, 69]. The interactions do not occur in ex vivo measures of platelet function, which are poor indicators of in vivo dynamics. PGI potently inhibits platelet aggregation, as it acts through the G-protein coupled receptor IP, which stimulates formation of cyclic AMP (cAMP) and suppresses platelet aggregation. PGI synthase is impaired by oxidants formed during transient postprandial conditions and vascular inflammation. The progressive accumulation of inflammatory atherosclerotic plaques increases the risk of triggering fatal thrombotic events.

\subsubsection{Anti-inflammatory Drugs and Fish Oil}

Important insight into excessive actions by $\mathrm{n}-6$ essential fatty acids came with recognition that aspirin inhibits the cyclooxygenase enzyme [70, 71] in a time-dependent, concentration-dependent, irreversible manner [72]. Successful moderation of the pathophysiology by a large number of aspirin-like anti-inflammatory drugs [73] confirmed that formation of eicosanoids from $n-6$ arachidonic acid is an important underlying process in CVD and its related comorbidities [8, 17]. Aspirin is accepted for immediate treatment of suspected thrombotic ischaemia, since it acts within minutes to stop platelet formation of pro-thrombotic $\mathrm{TXA}_{2}$. However, aspirin has a narrow therapeutic window before serious adverse events occur, as it blocks formation of beneficial eicosanoids (e.g. prostaglandins protect gastric mucosa, and PGI prevents thrombosis). As a result, continual use of $325 \mathrm{mg}$ doses of aspirin is not advised, to prevent the decades-long inflammatory vascular damage that eventually predisposes to thrombosis.

Low-dose aspirin $(85 \mathrm{mg})$ has a paradoxical ability to increase bleeding times, while a $325 \mathrm{mg}$ dose has no significant effect [69]. The non-nucleated platelets cannot use gene transcription and translation to replace the irreversibly inactivated cyclooxygenase [74, 75]. After a $325 \mathrm{mg}$ dose of aspirin, it takes several days for megakaryocytes to form enough new platelets to support thrombus formation. A careful and insightful review of six large primary prevention trials of aspirin [76] noted that low-dose aspirin avoided the serious bleeding seen with higher doses, but it gave no significant reductions in fatal coronary heart disease (CHD), stroke or vascular death (whereas secondary prevention trials involving impaired arteries had slightly fewer of those outcomes in patients allocated to aspirin). Two subsequent reports $[77,78]$ described an apparent lack of CVD risk reduction from primary prevention with lowdose aspirin.

However, Meade [76] noted that assessment of the overall benefits of primary prevention with aspirin should acknowledge reduced mortality from cancers (e.g. breast, colorectal and prostate cancers) that are promoted by cyclooxygenase products. Shifting the HUFA balance to prevent these and other $\mathrm{n}$-6-mediated comorbidities may be a positive intervention that avoids the narrow therapeutic windows of aspirin or LA (18:2n-6).

Intervention with n-3 HUFA (20:5n-3) reversibly reduces thromboxane formation and platelet aggregation [79]. The explosive synthetic capacity of platelets, which makes controlling thrombosis difficult to manage, was evident when thromboxane formation decreased in most patients who were treated, but aggregation decreased only when thromboxane formation was $<30 \mathrm{ng} / \mathrm{mL}$ [79]. Adding 20:5n-3 directly to platelets did not induce aggregation, even though some n-3 $\mathrm{TXA}_{3}$ was formed [80]. In contrast, adding 20:5n-3 to vascular tissue formed the anti-aggregatory prostacyclin $\mathrm{PGI}_{3}$ and shifted the platelet-vascular 
haemodynamic balance, which is important in predicting CVD risk. Later studies found that the n-3 HUFA 20:5n-3 forms $\mathrm{TXA}_{3}$ at about $10 \%$ of the rate at which the $\mathrm{n}-6$ HUFA 20:4n- 6 forms TXA $_{2}$ [81, 82]. The slower rate of formation of $\mathrm{TXA}_{3}$, combined with its rapid rate of decomposition, may leave little active ligand free to act with the TP receptor and cause thrombosis.

In contrast to the repeated beneficial associations for n-3 HUFA lifetime exposure in cross-national reports [13, 83], time-limited clinical trials of primary and secondary prevention of CVD have given confusing mixed messages. Casula et al. [84] assessed 11 randomized, double-blind, placebo-controlled trials selected from 360 articles and saw statistically significant protective effects for cardiac death (RR 0.68), sudden death (RR 0.67) and myocardial infarction (RR 0.75) but not for all-cause mortality (RR $0.89)$ and stroke (RR 1.31). The analysis included no assessment of intake of competing n-6 nutrients or of the tissue HUFA balance before and after the nutritional intervention. The biomarker $\% \mathrm{n}-6$ in HUFA is able to measure compliance and the extent of change in the HUFA balance to better inform interpretations of how an intervention altered risk. It ranged widely (from 25 to $85 \% \mathrm{n}-6$ in HUFA) in cross-national comparisons but likely differed less in time-limited clinical trials with homogeneous groups, which gave insufficient attention to creating a balance in n-3 and n-6 HUFA [17].

Wen et al. [85] evaluated 14 randomized, controlled trials picked from 3983 records. With no assessment of competing n- 6 nutrient intakes or the tissue HUFA balance before and after intervention, the investigators concluded that use of $n-3$ HUFA supplements in CHD patients had no protective effect on major cardiovascular events. However, use of $n-3$ HUFA supplements was associated with reduced death from cardiac causes, sudden cardiac death and death from all causes. Rizos et al. [86] evaluated 20 studies from 3635 publications (18 using supplements), again with no assessment of the competing n- 6 nutrient intakes or of any change in the tissue HUFA balance. Overall, intakes of $0.53-1.80 \mathrm{~g}$ of n-3 HUFA per day was not associated with lower allcause mortality, cardiac death, sudden death, myocardial infarction or stroke. To better interpret results from randomized clinical trials, future investigators might design robust alterations of the HUFA balance [17] and gather data on important biomarkers of dosage and dynamics.

\section{Balancing Dose Dynamics and Saturable Sites}

\subsection{Basic Receptor Dynamics}

In the early twentieth century, chemists knew that reaction rates increased linearly with the concentrations of reactants. When some enzyme-catalysed rates responded linearly to enzyme concentration but not to reactant concentrations, people realized that catalysts (and receptors) have hyperbolic saturable dynamics. Catalysed rates (and receptor responses) follow a non-linear model: response $=V_{\max } /\left(1+K_{\mathrm{m}} / S\right)$, where increased amounts of the substrate $(S)$ increase responses until the maximal response $\left(V_{\max }\right)$ is approached, when the amounts of $S$ become several-fold greater than the half-maximal concentration $\left(K_{\mathrm{m}}\right)$. This characteristic hyperbolic saturation must be recognized when evaluating responses for an active site or receptor saturated with an agonist. Under this condition, receptor-mediated processes lack the linear dose-response behaviour seen with small amounts of a substrate. Such saturation occurs during platelet aggregation by TXA and during formation of n-6 HUFA from LA (18:2n-6). The lack of an observed change with a changing substrate likely indicates that the system is operating near a maximal response rather than not acting.

An expanded model describes how a competing ligand (I) decreases enzyme-catalysed rates or receptor responses: response $=V_{\max } /\left(1+\left(K_{\mathrm{m}}\left(1+I / K_{\mathrm{i}}\right)\right) / S\right)$. Increased amounts of an inhibitor (I) increase the apparent midmaximal amount (i.e. $\left.K_{\mathrm{m}}\left(1+I / K_{\mathrm{i}}\right)\right)$ and decrease the response with a given amount of substrate (especially when $I>K_{\mathrm{i}}$ ). This occurs continually during conversion of the competing 18-carbon essential nutrients, 18:2n-6 (LA) and 18:3n-3 (ALA), into corresponding 20-carbon HUFA. The two nutrients have similar conversion rates and similar $\mathrm{K}_{\mathrm{m}}$ values near $0.1 \%$ of food energy $(0.1 \mathrm{en} \%)$ [18]. However, a 10-fold greater supply of $n-6$ than $n-3$ nutrients in typical American foods competitively slows conversion of the n-3 nutrient into tissue n-3 HUFA (see blue circle in curve $\mathrm{C}$ in Fig. 3). In contrast, the 0.7 en $\%$ n-3 nutrient intake has little impact on conversion of 6 en\% 18:2n-6 nutrient into its n-6 HUFA (see blue circle in curve B in Fig. 3). The outcome is near-maximal formation of the tissue $n-6$ HUFA arachidonic acid (20:4n-6), with a low apparent ability of the n-3 nutrient to form n-3 HUFA. The low apparent ability is misunderstood by many people to be a fixed aspect of ALA action, but it will reverse when more n-3 than n-6 nutrient is eaten.

Like the metabolic formation of n-3 and n-6 HUFA from 18-carbon precursors, acyltransferase placement of n-3 and n-6 HUFA into the 2-position of tissue phospholipids also has competitive dynamics [25]. As a result, the vigorous supply of n-6 HUFA continually being made from LA (18:2n-6) raises the apparent mid-maximal amount (i.e. $\left.K_{\mathrm{m}}\left(1+I / K_{\mathrm{i}}\right)\right)$ for $\mathrm{n}-3$ HUFA accumulation in membrane phospholipids. This competition combines with a limited supply of n-3 HUFA formed from ALA (18:3n-3) to maintain a high average of $75-80 \% \mathrm{n}-6$ in the HUFA of Americans [12, 13, 18, 51]. This proportion is lowered by 


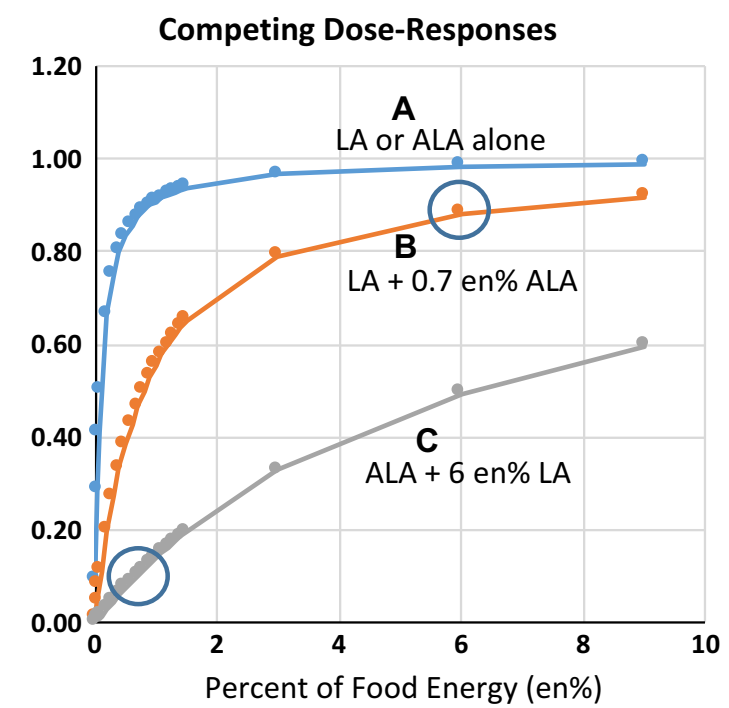

Fig. 3 Competing dose-responses in highly unsaturated fatty acid (HUFA) Formation. This simple model shows the fractional maximal responses of HUFA formation to dietary intake of precursors. It has a sensitive linear response to dietary intake of either 18:2n-6 linoleic acid (LA) or 18:3n-3 alpha-linolenic acid (ALA) alone from 0 to $0.5 \%$ of food energy ( 0 to $0.5 \mathrm{en} \%$ ), with a half-maximal response near $0.1 \mathrm{en} \%$ (curve A). In the presence of $0.7 \mathrm{en} \%$ ALA, the linear range of LA action is from 0 to $1.5 \mathrm{en} \%$, with a half-maximal response when both nutrients are near 0.7 en\% (curve B). Intake of ALA in the presence of 6 en\% LA forms n-3 HUFA, with a halfmaximal response near 6 en\% ALA (curve $C$ )

eating fewer $n-6$ nutrients with more $n-3$ nutrients. The competition of $n-3$ and n-6 HUFA for accumulation in membrane phospholipids needs to be monitored and reported to ensure that different clinical studies with different HUFA balances are appropriately combined and interpreted during meta-analyses.

After the 1964 discovery that both n-3 and n-6 HUFA form potent bioactive derivatives [87], it became evident that dietary n-3 HUFA could competitively moderate unwanted events mediated by n-6 HUFA [ $58,88,89]$. This made it useful to understand the quantitative relationship between average dietary intakes of n-3 and n- 6 nutrients and the HUFA balance in tissues to design effective dietary interventions to moderate HUFA-based health conditions. An empirical data-based hyperbolic model successfully fitted metabolic data for mice, rats and humans $[12,90]$. It also fitted diet-tissue data from nearly 4000 people in 92 subject groups in 34 published studies from 11 different countries (Strandjord, Lands and Hibbeln 2011; unpublished data).

The quantitative equation was embedded into software for convenient predictions of the impact that a dietary regimen would have on the tissue HUFA balance [91, 92]. In addition, an omega 3-6 balance score combines data for 11 n-3 and n- 6 nutrients in a food item to make readily visible the impact that each food item likely has on the health risk assessment biomarker \% n-6 in HUFA [50]. Foods with positive scores increase the $\% \mathrm{n}-3$ in HUFA, and those with negative scores increase the $\% \mathrm{n}-6$ in HUFA [93].

\subsection{Narrow Therapeutic Windows Create Problems}

The use of anti-thrombotic agents (aspirin, clopidogrel, dipyridamole, abciximab, heparin, dicoumarol and warfarin) provides many examples of a narrow therapeutic window for which the lowest effective dose is advised, with continual monitoring to avoid adverse events [21]. The need for strong interventions to slow the explosive amplifying action of $\mathrm{n}-6 \mathrm{TXA}_{2}$ during thrombus formation creates a problem when a low-dose drug is ineffective and more is excessive [19]. In contrast, fish oil interventions decrease the proportion of $n-6$ in the HUFA released during platelet activation, moderating n- 6 actions competitively without causing major adverse events [22]. In this way, fish oil widens the therapeutic window for $n-6$ nutrients [18] and permits safe long-term interventions.

In the absence of $n-3$ nutrients, the highly efficient conversion of dietary n- 6 LA into the n- 6 HUFA arachidonic acid allows LA at only 0.3 en\% to maintain about $50 \% \mathrm{n}-6$ in HUFA and prevent signs of essential fatty acid deficiency [18]. The mid-point in the dose-response curve was near 0.1 en $\%[18,51]$. In the absence of dietary n-3 nutrients, intakes above $0.5 \mathrm{en} \%$ linoleate maintain near $80 \% \mathrm{n}-6$ in HUFA. Importantly, people with $>50 \% \mathrm{n}-6$ in HUFA are at much greater risk of CVD death than those with $<50 \% \mathrm{n}-6$ in HUFA $[12,13,51]$. In the absence of dietary n-3 nutrients, eating less LA than the $0.1 \mathrm{en} \%$ that maintains $50 \%$ n-6 in HUFA may cause a deficiency, whereas eating $>0.5 \mathrm{en} \%$ increases the risk of many health conditions mediated by n-6 eicosanoids (Fig. 2). Current average USA intakes of 6-10 en\% LA far exceed the narrow therapeutic window of around 0.3 en\% [18], forming n-6 HUFA (20:4n-6) continually near maximal rates and suppressing n-3 HUFA storage. This is the reality into which we introduce dietary n-3 HUFA.

Successful handling of the competitive dynamics described above was achieved in a randomized, singleblind, parallel-group clinical trial, which used two diets with extensive dietitian counselling. Following a 4-week baseline period, patients ate (for 12 weeks) a diet with either much lower n-6 nutrients (L6) or low n-6 plus high n-3 HUFA (H3-L6) [94, 95]. The HUFA balance for the L6 group shifted only from 77.8 to $74.6 \%$ n-6 in HUFA, as expected for linoleate intakes far above its mid-maximal value (see curve B in Fig. 3). In contrast, the H3-L6 group shifted from 77.1 to $60.9 \%$ n-6 in HUFA, as dietary n-3 HUFA displaced n-6 HUFA. Importantly, the shifted HUFA balance caused the average hours per day of 
headaches to drop from 9.8 to 8.6 in L6 patients and from 10.2 to 5.6 in H3-L6 patients. Clearly, the lower \% n-6 in HUFA gave biologically important benefits.

\section{Planning for Benefits from Fish Oil Intervention}

\subsection{Treatment Versus Preventing the Need for Treatment}

The n-3 and n-6 HUFA in tissue phospholipids are the starting point of the arachidonic acid cascade [8], forming eicosanoids, which act on specific receptors affecting nearly all cells and tissues of the body. In general, formation and action of $n-6$ eicosanoids is more vigorous than that of n-3 eicosanoids [26]. Many unwanted health conditions listed in Fig. 2 involve excessive actions of $n-6$ eicosanoids $[14,18]$. This situation leads to the question of whether to treat the signs and symptoms of those conditions or to prevent the tissue imbalance that causes the signs and symptoms. Food choices that increase the proportions of n-3 HUFA (and decrease n-6 HUFA) in tissue phospholipids can decrease the risk of CVD and many other conditions made worse by n-6 eicosanoid actions. The harm from n-6 actions is clearly evident in the greater unintended CVD deaths from added n-6 LA $[5,96]$.

The Multiple Risk Factor Intervention Trial (MRFIT) was a randomized, primary prevention trial focusing on death from CHD. It involved 28 institutions, 250 investigators and 12,866 men monitored for $>7$ years [97]. Men aged 35-57 years were randomly assigned either to a special intervention (SI) programme or to their usual healthcare (UC). The CHD death rates were 17.9 per 1000 in the SI group and 19.3 per 1000 in the UC group, and the total death rates were 41.2 per 1000 (SI) and 40.4 per 1000 (UC). No beneficial effect on CHD or total mortality came from the multi-factor intervention [97]. However, the extensive data gave a useful insight regarding the HUFA balance. Serum phospholipids from 94 matched cases and controls had a HUFA balance of $78.7 \%$ n-6 in HUFA from cases compared with $76.5 \%$ n-6 in HUFA from controls [98].

Careful food intake data from the $6250 \mathrm{UC}$ men (see Table I in Ref. [99]), combined with the empirical model described in Sect. 4.1, give an overall predicted value of $78 \%$ n-6 in HUFA. Quintiles ranked by n-3 HUFA intake $(0.001,0.004,0.019,0.063$ and 0.272 en\%) [100] had predicted HUFA balance values of 82.8, 82.4, 80.9, 76.8 and $63.3 \%$ n-6 in HUFA, respectively [13]. Importantly, the lowest quintile of n-6 in HUFA had 24 deaths compared with 42 deaths in the highest quintile [13]. Similarly, Cree communities with HUFA balance values near $45 \%$ n- 6 in HUFA had less than half the CVD mortality of people in Quebec City with values near $75 \%$ n-6 in HUFA
[13]. The 1992 report (see Table VIII in Ref. [99]) also described the Japanese post-war trend in $n-3$ and $n-6$ intakes, which predicted a shifted HUFA balance from $1945(34 \%)$ to 1965 (46\%) and 1985 (55\%) in comparison with the MRFIT data from the late 1970s (81\%). These results point towards designing a primary prevention plan that informs participants of foods they can eat to shift their HUFA balance towards their desired personal HUFA balance goal [16, 91, 92]. Two simple, objective metrics in an individual's health record [14] document the progress and success of the plan in giving benefit: (1) the individual's previous and current values for the $\%$ n- 6 in the HUFA biomarker; and (2) the corresponding annual healthcare claims for that individual.

\subsection{Follow the Money}

Expensive, time-consuming CVD clinical trials became more controversial, and government funding became limited, after publication of the equivocal results from the $\$ 115$ million MRFIT and the $\$ 150$ million Coronary Primary Prevention Trial (CPPT) [3]. These findings led to a watershed in CVD research funding, as Cholesterol Consensus Conference experts urged dietary intervention to prevent CVD [33], while private sector organizations gained permission from the US Food and Drug Administration (FDA) to fund their own trials of their patented drugs (reviewed in detail in Sect. 7.2 of Ref. [51]). The NHLBI director described the change this way: “Today, if you don't call on the private sector, you are a lousy manager" [3]. Since then, widespread attention to statin treatments, rather than attention to diet priorities, have led to an obesity epidemic [51]. Treatments with patented drugs provide profit for a vast biomedical economy, but they are not needed for healthy people who have effective primary prevention. Support for developing effective primary prevention that balances n-3 and n- 6 nutrients will likely come from a sector that profits from preventing the need for treatments.

One special financial aspect of healthcare in the USA is the role that private corporations play in partnering with employees to pay for healthcare costs. A high percentage of large corporations self-fund their insurance for health-related financial risk. Employers pay for accounting services from insurance companies to handle day-to-day details, and 'catastrophic' insurance may be bought to cover exceptional risks. Most medical and pharmacy costs are covered jointly by employers and employees. When healthy employees need no treatments, corporate funds readily go to other priorities, such as acquisition of property, salary increases or new personnel. This makes it profitable to promote primary prevention in the context of a wellness programme that helps employees be well and free from the need for treatments $[13,14,16]$. 
Occupational medicine experts indicate that corporate losses from absenteeism and presenteeism are several-fold greater than those for medical and pharmacy costs [15]. These unrecognized losses add to the documented burden of $\$ 3$ trillion for healthcare in the USA [16]. The large financial incentive in shifting funds to new priorities whenever employees are healthy could prompt existing wellness plans to counsel and coach employees about foods that improve the HUFA balance and lower the risk of CVD and other n-6-based chronic health conditions. Prescriptions are not needed to make informed food choices that give healthy HUFA balances. The relevant apps and information are freely available [92, 93].

Fragments of data indicate that annual healthcare costs and CVD risk relate similarly to people's food-based HUFA balance [14]. When informed food choices shift the HUFA balance and many employee chronic health conditions are lessened, employers will likely see multiple-fold returns on their investment in primary prevention of HUFA-based conditions. Dietary fish oil could be a successful supplement in primary preventive interventions of CVD that balance the intakes of $n-3$ and $n-6$ nutrients and maintain balanced n-3 and n-6 HUFA in tissues.

\section{Conclusions}

CVD involves decades-long atherogenic inflammatory damage of vascular endothelium, which predisposes vessels to explosively rapid platelet-mediated thrombotic actions. Both processes are amplified by positive feedback signals with n-6 HUFA-based eicosanoids and are moderated by competing n-3 HUFA from fish oil. Interventions that lower the competing n-6 HUFA allow supplemental n-3 HUFA to be more effective. The balance of HUFA in blood normally ranges from $25 \% \mathrm{n}-6$ in HUFA to $85 \%$ n-6 in HUFA, and observational studies show that cardiovascular death rates are lower in populations that maintain $<50 \% \mathrm{n}-6$ in HUFA of blood lipids. This evidence indicates that balancing n-3 and n-6 HUFA in tissues with fish oil can be a successful intervention for the atherogenesis and thrombosis of CVD. The explosive thrombosis that is activated by impaired vascular endothelium requires vigorous suppression of many thrombogenic mediators, and most anti-thrombotic agents have narrow therapeutic windows that limit their use. Fish oil interventions could be safe in high enough doses to shift the HUFA balance significantly and lower platelet function, especially if competing dietary n-6 nutrients are kept at levels below 2 en\%.

Clinical trials focused on primary prevention of CVD need to begin before significant vascular damage occurs, and they require effective dietary intervention with thousands of people for many years to give statistically significant reductions in clinical end points. Limited funds and low interest from the research community have delayed the designing of effective primary prevention studies. Lowering the \% $\mathrm{n}-6$ in HUFA and the signals from n-6 HUFA-based eicosanoids that exacerbate many health conditions gives many benefits, as it lowers the risks of these comorbidities. As a result, interest in and funding for robust long-term interventions that lower the HUFA balance and its health-related financial losses may fit the priorities of USA employers rather than traditional governmental and pharmaceutical research organizations.

Acknowledgments The author thanks Catharine Clark and Norberta Schoene for their advice on manuscript preparation.

\section{Compliance with Ethical Standards}

Funding No sources of funding were used in the preparation of this review.

Conflict of interest Bill Lands has no conflicts of interest to declare that are directly relevant to the content of this manuscript.

Open Access This article is distributed under the terms of the Creative Commons Attribution-NonCommercial 4.0 International License (http://creativecommons.org/licenses/by-nc/4.0/), which permits any noncommercial use, distribution, and reproduction in any medium, provided you give appropriate credit to the original author(s) and the source, provide a link to the Creative Commons license, and indicate if changes were made.

\section{References}

1. Centers for Disease Control and Prevention. Chronic disease overview 2015. http://www.cdc.gov/chronicdisease/overview/. Accessed June 2016.

2. National Heart, Lung, and Blood Institute. Fact book fiscal year 2012. 2013. http://www.nhlbi.nih.gov/about/factpdf.htm. Accessed June 2016.

3. Kolata G. Heart institute is major player in clinical trials. Science. 1987;237(4817):851-3.

4. The Look AHEAD Research Group, Wing RR, Bolin P, Brancati FL, Bray GA, Clark JM, Coday M, Crow RS, Curtis JM, Egan CM, Espeland MA, Evans M, Foreyt JP, Ghazarian S, Gregg EW, Harrison B, Hazuda HP, Hill JO, Horton ES, Hubbard VS, Jakicic JM, Jeffery RW, Johnson KC, Kahn SE, Kitabchi AE, Knowler WC, Lewis CE, Maschak-Carey BJ, Montez MG, Murillo A, Nathan DM, Patricio J, Peters A, PiSunyer X, Pownall H, Reboussin D, Regensteiner JG, Rickman AD, Ryan DH, Safford M, Wadden TA, Wagenknecht LE, West DS, Williamson DF, Yanovski SZ. Cardiovascular effects of intensive lifestyle intervention in type 2 diabetes. N Engl J Med 2013;369:145-54. http://www.ncbi.nlm.nih.gov/pmc/articles/ PMC3791615/pdf/nihms-508996.pdf. Accessed June 2016.

5. Ramsden CE, Zamora D, Majchrzak-Hong S, Faurot KR, Broste SK, Frantz RP, Davis JM, Ringel A, Suchindran CM, Hibbeln JR. Re-evaluation of the traditional diet-heart hypothesis: analysis of recovered data from Minnesota Coronary Experiment (1968-73). BMJ. 2016;12(353):i1246. doi:10.1136/bmj. i1246. 
6. The ACCORD Study Group. Long-term effects of intensive glucose lowering on cardiovascular outcomes. N Engl J Med. 2011;364(9):818-28. http://www.ncbi.nlm.nih.gov/pmc/articles/ PMC4083508/pdf/nihms278789.pdf. Accessed June 2016.

7. Studer M, Briel M, Leimenstoll B, Glass TR, Bucher HC. Effect of different antilipidemic agents and diets on mortality: a systematic review. Arch Intern Med. 2005;165(7):725-30.

8. Lands B. Omega-3 PUFAs lower the propensity for arachidonic acid cascade overreactions. Biomed Res Int. 2015;2015:285135. http://www.hindawi.com/journals/bmri/2015/285135/. Accessed June 2016.

9. Lands B. Cholesterol: the most misunderstood marker. In: Watson R, De Meester F, editors. Handbook of cholesterol: biology, function and role in health and diseases. Wageningen: Wageningen Academic Publishers; 2016.

10. Mizushima S, Moriguchi EH, Ishikawa P, Hekman P, Nara Y, Mimura G, Moriguchi Y, Yamori Y. Fish intake and cardiovascular risk among middle-aged Japanese in Japan and Brazil. J Cardiovasc Risk. 1997;4(3):191-9.

11. Iso H, Sato S, Folsom AR, Shimamoto T, Terao A, Munger RG, Kitamura A, Konishi M, Iida M, Komachi Y. Serum fatty acids and fish intake in rural Japanese, urban Japanese, Japanese American and Caucasian American men. Int $\mathrm{J}$ Epidemiol. 1989;18(2):374-81

12. Lands WEM, Libelt B, Morris A, Kramer NC, Prewitt TE, Bowen P, Schmiesser D, Davidson MH, Burns JH. Maintenance of lower proportions of $n-6$ eicosanoid precursors in phospholipids of human plasma in response to added dietary n-3 fatty acids. Biochem Biophys Acta. 1992;1180:147-62.

13. Lands WEM. Diets could prevent many diseases. Lipids. 2003;38(4):317-21.

14. Lands B. Prevent the cause, not just the symptoms. Prostaglandins Other Lipid Mediators. 2011;296:90-3.

15. Loeppke R, Taitel M, Haufle V, Parry T, Kessler RC, Jinnett K. Health and productivity as a business strategy: a multiemployer study. J Occup Environ Med. 2009;51(4):411-28. doi:10.1097/ JOM.0b013e3181a39180.

16. Clark C, Lands B. Creating benefits from omega-3 functional foods and nutraceuticals. Food aNutr Sci. 2015;6:1613-23. http://www.scirp.org/journal/PaperInformation.aspx?PaperID= 62148. Accessed June 2016.

17. Bibus D, Lands B. Balancing proportions of competing omega-3 and omega-6 highly unsaturated fatty acids (HUFA) in tissue lipids. Prost Leuko Essent Fatty Acids. 2015;99:19-23. http:// www.plefa.com/article/S0952-3278(15)00087-3/pdf. Accessed June 2016

18. Lands B. Historical perspectives on the impact of $n-3$ and $n-6$ nutrients on health. Prog Lipid Res. 2014;55:17-29. http://www. sciencedirect.com/science/article/pii/S0163782714000253. Accessed June 2016.

19. FDA Drug Safety Communication. FDA strengthens warning that non-aspirin nonsteroidal anti-inflammatory drugs (NSAIDs) can cause heart attacks or strokes. 2015. http://www.fda.gov/ Drugs/DrugSafety/ucm451800.htm. Accessed June 2016.

20. Lands B. A balanced approach to omega- 3 benefits. PUFA Newsl. 2015;20(2):38-41. http://www.fatsoflife.com/wpcontent/uploads/2015/08/PUFA0815.pdfLands2015. Accessed June 2016.

21. Mehta, P., Mason, J.C. NSAIDs and coxibs: the stomach, the heart and the brain. Arthritis Research, UK. 2010. http://www. arthritisresearchuk.org/health-professionals-and-students/reports/ topical-reviews/topical-reviews-spring-2010.aspx. Accessed June 2016.

22. EFSA Panel on Dietetic Products, Nutrition and Allergies (NDA). European Food Safety Authority. Scientific opinion on the tolerable upper intake level of eicosapentaenoic acid (EPA), docosahexaenoic acid (DHA) and docosapentaenoic acid (DPA). EFSA J. 2012;10(7):1-48, doi:10.2903/j.efsa.2012.2815. https:// www.efsa.europa.eu/en/efsajournal/pub/2815.

23. Hodson L, Skeaff CM, Fielding BA. Fatty acid composition of adipose tissue and blood in humans and its use as a biomarker of dietary intake. Prog Lipid Res. 2008;47:348-80.

24. Plasma FA biomarkers-The Centers for Disease Control and Prevention (CDC) Division of Laboratory Sciences at the National Center for Environmental Health (NCEH/DLS). Second national report on biochemical indicators of diet and nutrition in the US population. 2012. http://www.cdc.gov/ nutritionreport/report.html. Accessed June 2016.

25. Lands WEM, Inoue $M$, Sugiura Y, Okuyama H. Selective incorporation of polyunsaturated fatty acids into phosphatidylcholine by rat liver microsomes. J Biol Chem. 1982;257:14968-72.

26. Wada M, DeLong CJ, Hong YH, Rieke CJ, Song I, Sidhu RS, Yuan C, Warnock M, Schmaier AH, Yokoyama C, Smyth EM, Wilson SJ, FitzGerald GA, Garavito RM, Sui de X, Regan JW, Smith WL. Enzymes and receptors of prostaglandin pathways with arachidonic acid-derived versus eicosapentaenoic acid derived substrates and products. J Biol Chem. 2007;282(31):22254-66. http://www.jbc.org/content/282/31/ 22254.full.pdf. Accessed June 2016.

27. Ross R. Atherosclerosis-an inflammatory disease. N Engl J Med. 1999;340:115-26.

28. Strong JP, Malcom GT, McMahan CA, Tracy RE, Newman WP III, Herderick EE, et al. Prevalence and extent of atherosclerosis in adolescents and young adults: implications for prevention from the Pathobiological Determinants of Atherosclerosis in Youth (PDAY) Research Group. JAMA. 1999;281(8):727-35.

29. Ku DN, Giddens DP, Zarins CK, Glagov S. Pulsatile flow and atherosclerosis in the human carotid bifurcation. Positive correlation between plaque location and low oscillating shear stress. Arteriosclerosis. 1985;5(3):293-302.

30. Giddens DP, Zarins CK, Glagov S. The role of fluid mechanics in the localization and detection of atherosclerosis. J Biomech Eng. 1993;115(4B):588-94.

31. Keys A, Anderson JT, Mickelsen O. Serum cholesterol in men in basal and nonbasal states. Science. 1956;123:29.

32. Oliver MF. Diet and coronary heart disease. Hum Nutr Clin Nutr. 1982;36(6):413-27.

33. Conference Consensus. Lowering blood cholesterol to prevent heart disease. JAMA. 1985;253(14):2080-6.

34. Urban LE, Lichtenstein AH, Gary CE, Fierstein JL, Equi A, Kussmaul C, Dallal GE, Roberts SB. The energy content of restaurant foods without stated calorie information. JAMA Intern Med. 2013;173(14):1-8.

35. Vogel RA, Corretti MC, Plotnick GD. Effect of a single high-fat meal on endothelial function in healthy subjects. Am J Cardiol. 1997;79(3):350-4.

36. Gaenzer H, Sturm W, Neumayr G, Kirchmair R, Ebenbichler C, Ritsch A, Föger B, Weiss G, Patsch JR. Pronounced postprandial lipemia impairs endothelium-dependent dilation of the brachial artery in men. Cardiovasc Res. 2001;52(3):509-16.

37. Xiang GD, Xiang LW, He HL, Zhao LS. Postprandial lipaemia suppresses endothelium-dependent arterial dilation in patients with hypothyroidism. Endocrine. 2012;42(2):391-8.

38. Nyby MD, Matsumoto K, Yamamoto K, Abedi K, Eslami P, Hernandez G, Smutko V, Berger ME, Tuck ML. Dietary fish oil prevents vascular dysfunction and oxidative stress in hyperinsulinemic rats. Am J Hypertens. 2005;18(2 Pt 1):213-9.

39. van Oostrom AJ, Sijmonsma TP, Verseyden C, Jansen EH, de Koning EJ, Rabelink TJ, Castro Cabezas M. Postprandial recruitment of neutrophils may contribute to endothelial dysfunction. J Lipid Res. 2003;44(3):576-83. 
40. Grenon SM, Aguado-Zuniga J, Hatton JP, Owens CD, Conte MS, Hughes-Fulford M. Effects of fatty acids on endothelial cells: inflammation and monocyte adhesion. J Surg Res. 2012;177(1):e35-43.

41. Sun R, Wang X, Liu Y, Xia M. Dietary supplementation with fish oil alters the expression levels of proteins governing mitochondrial dynamics and prevents high-fat diet-induced endothelial dysfunction. Br J Nutr. 2014;112(2):145-53.

42. Wu S-Y, Mayneris-Perxachs J, Lovegrove JA, Todd S, Yaqoob P. Fish-oil supplementation alters numbers of circulating endothelial progenitor cells and microparticles independently of eNOS genotype. Am J Clin Nutr. 2014;100(5):1232-43. http:// ajcn.nutrition.org/content/100/5/1232.long. Accessed June 2016.

43. Spigoni V, Lombardi C, Cito M, Spigoni V, Lombardi C, Cito M, Picconi A, Ridolfi V, Andreoli R, Anelli N, Gnudi L, Goldoni M, Zavaroni I, Raddino R, Dei Cas A. N-3 PUFA increase bioavailability and function of endothelial progenitor cells. Food Funct. 2014;5(8):1881-90.

44. Turgeon J, Dussault S, Maingrette F, Groleau J, Haddad P, Perez G, Rivard A. Fish oil-enriched diet protects against ischemia by improving angiogenesis, endothelial progenitor cell function and postnatal neovascularization. Atherosclerosis. 2013;229(2): 295-303.

45. Subbarao K, Jala VR, Mathis S, Suttles J, Zacharias W, Ahamed J, Ali H, Tseng MT, Haribabu B. Role of leukotriene B4 receptors in the development of atherosclerosis: potential mechanisms. Arterioscler Thromb Vasc Biol. 2004;24(2): 369-75.

46. Ketelhuth DF, Hermansson A, Hlawaty H, Letourneur D, Yan ZQ, Bäck M. The leukotriene B4 receptor (BLT) antagonist BIIL284 decreases atherosclerosis in ApoE(-/-) mice. Prostaglandins Other Lipid Mediat. 2015;121(Pt A):105-9.

47. Lee TH, Sethi T, Crea AE, Peters W, Arm JP, Horton CE, et al. Characterization of leukotriene B3: comparison of its biological activities with leukotriene B4 and leukotriene B5 in complement receptor enhancement, lysozyme release and chemotaxis of human neutrophils. Clin Sci (Lond). 1988;74(5):467-75.

48. Verschuren WM, Jacobs DR, Bloemberg BP, Kromhout D, Menotti A, Aravanis C, Blackburn H, Buzina R, Anastasios S, Dontas AS, Fidanza F, Karvonen MJ, Nedelijkovic S, Nissinen A, Toshima H. Serum total cholesterol and long-term coronary heart disease mortality in different cultures. Twenty-five year follow-up of the Seven Countries Study. JAMA. 1995;274(2):131-6.

49. Toshima H, Koga Y, Menotti A, Keys A, Blackburn H, Jacobs DR, Seccareccia F. The seven countries study in Japan. Twentyfive-year experience in cardiovascular and all-causes deaths. Jpn Heart J. 1995;36(2):179-89.

50. Lands B. Lamoreaux E, Describing essential fatty acid balance as 3-6 differences rather than $3 / 6$ ratios. Nutr Metab. 2012;9:46-54. http://www.ncbi.nlm.nih.gov/pmc/articles/ PMC3533819/pdf/1743-7075-9-46.pdf. Accessed June 2016.

51. Lands B. A critique of paradoxes in current advice on dietary lipids. Prog Lipid Res. 2008;47(2):77-106.

52. Skarke C, Alamuddin N, Lawson JA, Li X, Ferguson JF, Reilly MP, FitzGerald GA. Bioactive products formed in humans from fish oils. J Lipid Res. 2015;56(9):1808-20.

53. Ren Q, Ye S, Whiteheart SW. The platelet release reaction: just when you thought platelet secretion was simple. Curr Opin Hematol. 2008;15(5):537-41. http://www.ncbi.nlm.nih.gov/ pmc/articles/PMC2665692/pdf/nihms89899.pdf. Accessed June 2016.

54. Li Z, Delaney MK, O’Brien KA, Du X. Signaling during platelet adhesion and activation. Arterioscler Thromb Vasc Biol. 2010;30(12):2341-9. http://www.ncbi.nlm.nih.gov/pmc/articles/ PMC3085271/pdf/nihms252820.pdf. Accessed June 2016.
55. FitzGerald GA. Mechanisms of platelet activation: thromboxane $A_{2}$ as an amplifying signal for other agonists. Am J Cardiol. 1991;68(7):11B-5B.

56. Hamberg M, Svensson J, Samuelsson B. Thromboxanes: a new group of biologically active compounds derived from prostaglandin endoperoxides. Proc Natl Acad Sci USA. 1975;72(8):2994-8. http://www.ncbi.nlm.nih.gov/pmc/articles/ PMC432905/pdf/pnas00051-0164.pdf. Accessed June 2016.

57. Lands WEM, Lee RE, Smith WL. Factors regulating the biosynthesis of various prostaglandins. Ann N Y Acad Sci. 1971;180:107-22.

58. Lands WEM, LeTellier PR, Rome LH, Vanderhoek JY. Inhibition of prostaglandin biosynthesis. Adv Biosci. 1973;9:15-28. In: Bergstrom S, Bernhard S, editors. International conference on prostaglandins, Vienna, 25-28 September 1972. Pergamon Press, Vieweg, Oxford.

59. Cook HW, Lands WEM. A mechanism for the suppression of cellular biosynthesis of prostaglandins. Nature. 1976;260:630-2.

60. Hemler ME, Lands WEM. Evidence for a peroxide-initiated free radical mechanism of prostaglandin biosynthesis. J Biol Chem. 1980;255:6253-61. http://www.jbc.org/content/255/13/6253. long. Accessed June 2016.

61. Lands WEM, Hanel AM. Phenolic anti-cyclooxygenase agents and hypotheses of antiinflammatory therapy. Prostaglandins. 1982;24:271-8

62. Hanel AM, Lands WEM. Modification of antiinflammatory drug effectiveness by ambient lipid peroxides. Biochem Pharmacol. 1982;31:3307-11.

63. Culp BR, Titus BR, Lands WEM. Inhibition of prostaglandin biosynthesis by eicosapentaenoic acid. Prostaglandins Med. 1979;3:269-78

64. Kulmacz RJ, Pendleton RB, Lands WEM. Interaction between peroxidase and cyclooxygenase activities in prostaglandin-endoperoxide synthase. J Biol Chem. 1994;269(8):5527-36.

65. Reilly IA, FitzGerald GA. Inhibition of thromboxane formation in vivo and ex vivo: implications for therapy with platelet inhibitory drugs. Blood. 1987;69(1):180-6.

66. Whittaker N, Bunting S, Salmon J, Moncada S, Vane JR, Johnson RA, Morton DR, Kinner JH, Gorman RR, McGuire JC, Sun FF. The chemical structure of prostaglandin X (prostacyclin). Prostaglandins. 1976;12(6):915-28.

67. Moncada S, Vane JR. Arachidonic acid metabolites and the interactions between platelets and blood-vessel walls. N Engl J Med. 1979;300(20):1142-7.

68. Vane JR. Prostacyclin. J R Soc Med. 1983;76(4):245-9.

69. O'Grady J, Moncada S. Aspirin: a paradoxical effect on bleeding-time. Lancet. 1978;2(8093):780.

70. Ferreira SH, Moncada S, Vane JR. Indomethacin and aspirin abolish prostaglandin release from the spleen. Nat New Biol. 1971;231(25):237-9.

71. Vane JR. Inhibition of prostaglandin synthesis as a mechanism of action for aspirin-like drugs. Nat New Biol. 1971;231(25):232-5.

72. Smith WL, Lands WEM. Stimulation and blockade of prostaglandin synthesis. J Biol Chem. 1971;246:6700-4. http:// www.jbc.org/content/246/21/6700.long. Accessed June 2016.

73. Funk CD, FitzGerald GA. COX-2 inhibitors and cardiovascular risk. J Cardiovasc Pharmacol. 2007;50(5):470-9.

74. Weksler BB, Pett SB, Alonso D, Richter RC, Stelzer P, Subramanian V, Tack-Goldman K, Gay WA Jr. Differential inhibition by aspirin of vascular and platelet prostaglandin synthesis in atherosclerotic patients. $\mathrm{N}$ Engl J Med. 1983;308(14):800-5.

75. De Caterina R, Giannessi D, Bernini W, Gazzetti P, Michelassi C, L'Abbate A, Donato L, Patrignani P, Filabozzi P, Patrono C. Low-dose aspirin in patients recovering from myocardial 
infarction. Evidence for a selective inhibition of thromboxanerelated platelet function. Eur Heart J. 1985;6(5):409-17.

76. Meade T. Primary prevention of ischaemic cardiovascular disorders with antiplatelet agents. Handb Exp Pharmacol. 2012;210:565-605.

77. Ikeda Y, Shimada K, Teramoto T, Uchiyama S, Yamazaki T, Oikawa S, Sugawara M, Ando K, Murata M, Yokoyama K, Ishizuka N. Low-dose aspirin for primary prevention of cardiovascular events in Japanese patients 60 years or older with atherosclerotic risk factors. A randomized clinical trial. JAMA. 2014;312(23):2510-20.

78. Sasso FC, Marfella R, Pagano A, Porta G, Signoriello G, Lascar N, Minutolo R, Carbonara O, Persico M, Piscione F, De Nicola L, Torella R, Paolisso G. Lack of effect of aspirin in primary CV prevention in type 2 diabetic patients with nephropathy: results from 8 years follow-up of NID-2 study. Acta Diabetol. 2015;52(2):239-47.

79. Lands WEM, Culp BR, Hirai A, Gorman R. Relationship of thromboxane generation to the aggregation of platelets from humans: effects of eicosapentaenoic acid. Prostaglandins. 1985;30:819-25.

80. Dyerberg J, Bang HO, Stoffersen E, Moncada S, Vane JR. Eicosapentaenoic acid and prevention of thrombosis and atherosclerosis? Lancet. 1978;2(8081):117-9.

81. Hamazaki T, Fischer S, Schweer H, Meese CO, Urakaze M, Yokoyama A, Yano S. The infusion of trieicosapentaenoylglycerol into humans and the in vivo formation of prostaglandin I3 and thromboxane $\mathrm{A}_{3}$. Biochem Biophys Res Commun. 1988;151(3):1386-94.

82. Krämer HJ, Stevens J, Grimminger F, Seeger W. Fish oil fatty acids and human platelets: dose-dependent decrease in dienoic and increase in trienoic thromboxane generation. Biochem Pharmacol. 1996;52(8):1211-7.

83. Hibbeln JR, Nieminen LR, Blasbalg TL, Riggs JA, Lands WE. Healthy intakes of n-3 and n- 6 fatty acids: estimations considering worldwide diversity. Am J Clin Nutr. 2006;83(6 Suppl):1483S-93S. http://ajcn.nutrition.org/content/ 83/6/S1483.full.pdf+html. Accessed June 2016.

84. Casula M, Soranna D, Catapano AL, Corrao G. Long-term effect of high dose omega-3 fatty acid supplementation for secondary prevention of cardiovascular outcomes: a meta-analysis of randomized, placebo controlled trials (corrected). Atheroscler. 2013;14(Suppl. 2):243-51.

85. Wen YT, Dai JH, Gao Q. Effects of omega-3 fatty acid on major cardiovascular events and mortality in patients with coronary heart disease: a meta-analysis of randomized controlled trials. Nutr Metab Cardiovasc Dis. 2014;24(5):470-5.

86. Rizos EC, Ntzani EE, Bika E, Kostapanos MS, Elisaf MS. Association between omega-3 fatty acid supplementation and risk of major cardiovascular disease events: a systematic review and meta-analysis. JAMA. 2012;308(10):1024-33.
87. Samuelsson B. An elucidation of the arachidonic acid cascade: discovery of prostaglandins, thromboxane and leukotrienes. Drugs. 1987;33(Suppl. 1):2-9.

88. Lands WE, Pitt BW, Culp BR. Recent concepts on platelet function and dietary lipids in coronary thrombosis, vasospasm and angina. Herz. 1980;5(1):34-41.

89. Lands B. Consequences of essential fatty acids. Nutrients. 2012;4(9):1338-57.

90. Lands WEM. Functional foods in primary prevention or nutraceuticals in secondary prevention? Curr Top Nutraceut Res. 2003;1(2):113-20.

91. Calculator. http://efaeducation.org/?p=124. Accessed June 2016.

92. Apps for planning. http://efaeducation.org/omega-3-6-apps/. Accessed June 2016.

93. Website food scores. http://omega3scores.com/. Accessed June 2016.

94. MacIntosh BA, Ramsden CE, Faurot KR, Zamora D, Mangan M, Hibbeln JR, et al. Low-n-6 and low-n-6 plus high-n-3 diets for use in clinical research. Br J Nut 2013;110(3):559-68. doi:10.1017/S0007114512005181. Accessed June 2016.

95. Ramsden CE, Faurot KR, Zamora D, Suchindran CM, Macintosh BA, Gaylord S, Ringel A, Hibbeln JR, Feldstein AE, Mori TA, Barden A, Lynch C, Coble R, Mas E, Palsson O, Barrow DA, Mann JD. Targeted alteration of dietary n-3 and n- 6 fatty acids for the treatment of chronic headaches: a randomized trial. Pain. 2013;154(11):2441-51. http://www.ncbi.nlm.nih.gov/pmc/ articles/PMC3850757/pdf/nihms514426.pdf. Accessed June 2016.

96. Ramsden CE, Zamora D, Leelarthaepin B, Majchrzak-Hong SF, Faurot KR, Suchindran CM, Ringel A, Davis JM, Hibbeln JR. Use of dietary linoleic acid for secondary prevention of coronary heart disease and death: evaluation of recovered data from the Sydney Diet Heart Study and updated meta-analysis. BMJ. 2013;346:e8707. doi:10.1136/bmj.e8707. http://www.ncbi.nlm. nih.gov/pmc/articles/PMC4688426/. Accessed June 2016 (Erratum in: BMJ. 2013;346:f903).

97. MRFIT Intervention Trial Research Group. Multiple Risk Factor Intervention Trial risk factor changes and mortality results. JAMA. 1982;248:1465-77.

98. Simon JA, Hodgkins ML, Browner WS, Neuhaus JM, Bernert JT, Hulley SB. Serum fatty acids and the risk of coronary heart disease. Am J Epidemiol. 1995;142:469-76.

99. Dolecek TA. Epidemiological evidence of relationships between dietary polyunsaturated fatty acids and mortality in the Multiple Risk Factor Intervention Trial. Proc Soc Exp Biol Med. 1992;200(2):177-82.

100. Dolecek TA, Granditis G. Dietary polyunsaturated fatty acids and mortality in the Multiple Risk Factor Intervention Trial (MRFIT). World Rev Nutr Diet. 1991;66:205-16. 